\title{
REGULATION OF SYNAPTIC POSITION, SIZE, AND STRENGTH IN ANURAN SKELETAL MUSCLE ${ }^{1}$
}

\author{
BRUCE M. NUDELL ${ }^{2}$ AND ALAN D. GRINNELL \\ Departments of Biology and Physiology, Jerry Lewis Neuromuscular Research Center, Ahmanson Laboratory for \\ Neurobiology, University of California, Los Angeles, Los Angeles, California 90024
}

Received April 7, 1982; Revised June 14, 1982; Accepted June 14, 1982

\begin{abstract}
An analysis of the physiology, morphology, and position of endplates on identified fibers in the Xenopus laevis pectoralis muscle has revealed the following.

1. The percentage of fibers with one endplate is lower in large muscles, and within the same muscle, singly innervated fibers are smaller than dually innervated fibers.

2 . Single junctions tend to be stronger than junctions on dually innervated fibers.

3. Single junctions typically are located near the middle of their fibers, while the endplates on dually innervated fibers are located toward either end and usually are separated by at least $20 \%$ of the total fiber length. A significant proportion of dually innervated fibers appears to be innervated by the same axon at both junctions.

4. Junctions on the same dually innervated fiber tend to be more similar in length than do junctions on different fibers of the same input resistance. This observation is the same whether both junctions on a given fiber are formed by the same or different axons. There is no corresponding tendency for greater similarity in physiological strength of paired junctions, which frequently show large differences in endplate potential amplitude.

5. The total terminal length on dually innervated fibers of equivalent input resistance is inversely correlated with the mean release per unit length and total release of both junctions. There is no apparent correlation between the distance separating endplates and their strength or length.

The data support a model of synaptic regulation in which nerve terminals are attracted, grow, and are maintained in proportion to the amount of a substance supplied by muscle fibers. Our findings suggest that such a substance is produced or distributed uniformly throughout each fiber in amounts proportional to the fiber size and inversely proportional to the total transmitter output of all junctions innervating the fiber. A form of competitive interaction between the terminals which helps to determine synaptic spacing may involve local depletion or inactivation of this substance.
\end{abstract}

Frog neuromuscular junctions customarily are viewed as being synapses of relatively uniform structure and high safety margin (i.e., evoking postsynaptic depolarization well above threshold). In fact, however, it has long been recognized that even on frog twitch muscle fibers some junctions produce only subthreshold endplate potentials (EPPs) on single stimulation (Fatt and Katz, 1951; Kuffler, 1952; Luff and Proske, 1976; Grinnell and Herrera, 1980; Ridge and Thompson, 1980; see Grinnell

\footnotetext{
1 This work was supported by United States Public Health Service Grant NS 06232 and a center grant from the Muscular Dystrophy Association. We wish to thank Drs. A. D'Alonzo, A. Cangiano, D. CardLinden, A. A. Herrera, and W. Moody, and Mr. L. O. Trussell for helpful discussions during the research and preparation of this manuscript. We also thank Frances Knight and Don Simpson for expert technical assistance.

${ }^{2}$ To whom correspondence should be addressed.
}

and Herrera, 1981, for review), and far from being uniform in their properties, different junctions in the same muscle may differ dramatically in size and strength. Junctions in a given cutaneous pectoris muscle, for example, vary by as much as 4 -fold in size (terminal length) and 8-fold in amount of transmitter released per unit length in normal Ringer solution (Nudell and Grinnell, 1982). In the sartorius muscle, differences as great as 12fold in length and 25-fold in EPP amplitude and release per unit length have been found in the same muscle (Grinnell and Herrera, 1981; unpublished observations; Weakly, 1978). Moreover, junctional strength can be altered sharply by at least two kinds of experimental manipulation (Herrera and Grinnell, 1980, 1981), and it has been shown that terminals both grow and retract in the adult frog (Wernig et al., 1980).

It is well known that larger diameter muscle fibers 
tend to have larger junctions (Coërs, 1955; Anzenbacher and Zenker, 1963; Kuno et al., 1971; Bennett and Pettigrew, 1975; Harris and Ribchester, 1979). However, synapses of equal size may differ sharply in quantal content or EPP size, and frequently short terminals are stronger than longer ones. In a recent paper (Nudell and Grinnell, 1982), we demonstrated that in the Rana pipiens cutaneous pectoris muscle much of this variability can be explained by an inverse relationship between transmitter release per unit terminal length and terminal length for endplates on muscle fibers of equivalent input resistance. The findings in the cutaneous pectoris suggested that terminals with relatively low levels of release per unit length compensate for this by increased growth until an adequate safety margin for transmission is achieved.

We have now performed similar analyses for fibers in the Xenopus laevis pectoralis muscle, which, unlike the singly innervated cutaneous pectoris fibers, may have either one, two, or three endplate sites per fiber and in which individual surface fibers are exposed along their entire length. Our rationale for this study was twofold. We wanted to determine whether the same form of regulation of synaptic size that we described in the cutaneous pectoris is also found in the multiply innervated fibers of the pectoralis. In addition, we were interested in elucidating the nature and effects of competitive interactions between multiple terminals on the same muscle fiber. Competitive suppression and displacement of one synapse by another have been described in many different amphibian and mammalian preparations (for reviews, see Purves, 1976; Jansen et al., 1978; Mark, 1980; Lømo and Jansen, 1980; Grinnell and Herrera, 1981), and it has been shown in the Xenopus pectoralis preparation that the two junctions on dually innervated fibers can compete with each other and tend to be weaker than junctions on singly innervated fibers (Angaut-Petit and Mallart, 1979; Haimann et al., 1976, 1981a, b). In the present paper we show that in the pectoralis muscle there appear to be clearly recognizable rules that govern whether or not a fiber will be singly or doubly innervated, where the junctions will form, and the size and mean strength of the junctions on any given fiber, at least when both are formed by axons of the same nerve.

\section{Materials and Methods}

Preparation. Xenopus laevis of 3.7 to $7.6 \mathrm{~cm}$ length (nose to vent), weighing 10.8 to $44 \mathrm{gm}$, were obtained from the South African Snake Farm or, in early stages of the research, from ponds in Orange County CA. Animals were anesthetized by immersion in $0.01 \%$ tricaine methanosulfonate (Ayerst) and pithed, and the pectoralis muscle was dissected out and studied in vitro (see Haimann et al., 1981a, for a full description and drawing of this preparation). The pectoralis muscle is supplied by two nerves. These two nerves apparently contain separate populations of axons, since, if one nerve is cut near the muscle and that nerve is stimulated just central to the cut, no contraction is seen in fibers innervated by the other nerve. One nerve enters the muscle at its anterior edge and the other at the posterior edge. The anterior portion of the muscle is innervated exclusively by the anterior nerve, the posterior portion by the posterior nerve, and the middle portion by both nerves. We avoided this central region of overlapping innervation so that virtually all of the fibers studied in a particular experiment responded only to stimulation of one nerve. Most fibers had two discrete endplate sites, and the incidence of fibers with one endplate was correlated with muscle size (see below). (Some endplate sites receive input from more than one axon, but this is relatively uncommon (Haimann et al., 1981a). In the present study, we stimulated each nerve supramaximally and treated the total response as one junctional potential.) In our histological experiments we encountered a very small number of fibers with three endplates, for which we do not have physiological data.

Electrophysiology. Pectoralis muscles were stretched to about $110 \%$ of their in situ length and pinned to a thin layer of Sylgard (Dow Corning) lining the recording chamber. Within each experiment there was no more than $5 \%$ variability in the degree of stretch of different muscle fibers as judged by sarcomere spacing. This undoubtedly affected our assessment of synaptic strength as transmitter release in other frogs has been shown to be sensitive to the degree of muscle stretch (Hutter and Trautwein, 1956; Turkanis, 1973; Grinnell and Herrera, 1980). We consider it unlikely that this introduced a systematic bias into our results, however, as there is no reason to believe that intrinsically strong or weak junctions were stretched differentially.

Muscle fibers were impaled with glass micropipettes filled with $3 \mathrm{M} \mathrm{KCl}$ (20 to 40 megohms). To measure input resistance $\left(R_{\mathrm{in}}\right)$, a second micropipette, for current injection, was inserted in the same fiber within $50 \mu \mathrm{m}$. Fibers with resting potentials of less than $-80 \mathrm{mV}$ were rejected as were fibers in which both penetrations were not abrupt and stable. Input resistance typically was measured halfway along the fiber's length prior to searching for endplate sites. Input resistance was quite uniform along the length of a given fiber, differing by an average of only $8 \%(0.025 \mathrm{megohm})$ at the two endplate sites in 15 dually innervated fibers tested.

Even though each fiber was impaled repeatedly to locate endplate sites precisely, as judged by maximal rate of rise of the EPP, we feel that our rejection of fibers with less than $-80 \mathrm{mV}$ of resting potential eliminated electrode damage as an important source of error in our measurement of synaptic properties. We also tended to record from relatively large muscle fibers, which tolerated repeated electrode penetrations with only small decrements in resting potential. EPPs at one endplate had a negligible effect on recordings of EPPs at other endplates. In practice, the EPP generated at one endplate was found to contribute no more than 5 to $10 \%$ of its amplitude to the peak amplitude of a simultaneous EPP recorded at a second endplate on the fiber, and even these small contributions could only be seen in those few instances when pairs of junctions were separated by as little as 10 to $20 \%$ of the length of the fiber (see Fig. 5). Synaptic strength was assessed by taking the average of 5 EPPs evoked at $1 \mathrm{~Hz}$ in a Ringer solution $(1.8 \mathrm{~mm}$ $\mathrm{CaCl}_{2}, 116 \mathrm{~mm} \mathrm{NaCl}, 2 \mathrm{~mm} \mathrm{KCl}$, buffered to $\mathrm{pH} 7.2$ with approximately $1 \mathrm{mM} \mathrm{NaHCO}$ ) containing concentrations $\left(0.3\right.$ to $\left.1.0 \times 10^{-5} \mathrm{M}\right)$ of $d$-tubocurarine chloride (Nutritional Biochemicals) adequate to block muscle contrac- 
tion. In all EPP measurements synaptic potentials were normalized to a standard resting membrane potential of $-90 \mathrm{mV}$ (Katz and Thesleff, 1957). When we wanted to compare the absolute transmitter output of a number of junctions (see Figs. 9, 10, and 11), EPP amplitudes were normalized for muscle fiber $R_{\text {in }}$. Each EPP was multiplied by the ratio of the average input resistance of all fibers sampled to the input resistance of the fiber in question. We did not apply a correction for nonlinear summation (Martin, 1955), as recent work (McLachlan and Martin, 1981) has demonstrated that endplate potentials not in excess of $15 \%$ of the resting potential require only negligible corrections. We estimate that the release values calculated for the largest EPPs that we observed $(20 \mathrm{mV})$ were underestimated by about 10 to $15 \%$ due to the effects of nonlinear summation (McLachlan and Martin, 1981). The application of Martin's (1955) original correction (results not shown) would produce an overestimate of comparable magnitude and would steepen the slopes of the relationships seen between release or release per unit length and total terminal length. We did not attempt to obtain statistical estimates of quantal content (via the method of variations (Martin, 1955)) because of the theoretical difficulties of applying Poisson statistics to a binomial process, the longer series of responses necessary for meaningful estimates of amplitude variations, and the complicating effects of synaptic depression.

While it is possible that differences in postsynaptic sensitivity to acetylcholine (ACh) and/or acetylcholinesterase (AChE) activity could contribute to the observed variability in EPP size, we doubt that these effects are primarily responsible for the relationships described below. Justification for this comes from our previous work in the $R$. pipiens cutaneous pectoris preparation (Nudell and Grinnell, 1982) in which we demonstrated that miniature EPP amplitudes varied linearly with $R_{\text {in }}$, and plots of quantal content per unit terminal length (obtained in low $\mathrm{Ca}^{2+}$ Ringer solution) showed the same results as those of normalized EPP size per unit terminal length vs. terminal length.

Separation of motor units. To determine if the two endplates on dually innervated fibers were formed by the same or different axons, we simultaneously recorded EPPs at both sites and varied the stimulus intensity to the nerve. When the endplates were innervated by two axons of different threshold, the results were unambiguous. Endplates were judged to be formed by a single axon when EPPs at the two junctions appeared and failed to appear synchronously at a constant "threshold" stimulus intensity. Estimates of motor unit overlap achieved by this method may represent underestimates of the true value and must be confirmed by further studies of isolated single motor units.

Junctional morphology. At the time of recording, a drawing was made of the fiber, electrode position, and nearby landmarks to facilitate subsequent identification. Immediately after each physiological experiment, endplates were visualized with the combined nitro blue tetrazolium method of Letinsky and DeCino (1980) and the AChE method of Karnovsky (1964), as described in our earlier paper (Nudell and Grinnell, 1982). Terminal size was measured as the summed length of nerve branches lying within AChE-outlined synaptic gutters. Terminal length was normalized to a constant sarcomere spacing within each experiment.

We routinely measured terminal length rather than the area of synaptic contact because of the difficulty of making light microscopic assessments of terminal diameter. As a control, however, we sought to determine whether release per unit terminal length was well correlated with apparent terminal diameter in two Xenopus pectoralis muscles ( 25 endplates) and one $R$. pipiens cutaneous pectoris muscle (11 endplates). In none of the present experiments did we observe a statistically significant correlation between release per unit length and apparent terminal diameter (the correlation coefficients for the lines of best fit being $0.3(N=12), 0.14(N=13)$, and $0.2(N=11))$. The good correlation between terminal length and other synaptic parameters, described below, can be taken as additional evidence that length is regulated independently of apparent terminal diameter (see also Footnote 3).

Determination of release per unit length. Values for transmitter release per unit terminal length were calculated by dividing the average EPP amplitude, corrected for resting potential and $R_{\text {in }}$, by the terminal length in the case of fibers with one endplate and by dividing the summed mean EPP amplitudes of both junctions by their summed terminal lengths for fibers with two endplate sites.

Grouping of the data. Synaptic strength was assessed in 131 dually innervated and 14 singly innervated fibers in 21 muscles. A major aim of this study was to discern more clearly the relationship between synaptic effectiveness and terminal size. The efficacy of neuromuscular junctions depends both on the amount of transmitter released and the postsynaptic response to that transmitter. Previous studies have demonstrated that synaptic size and fiber diameter are directly correlated (see the introduction). Therefore, in order to study the interdependence of synaptic size and presynaptic release properties, we chose to analyze the relationship between these variables under conditions where postsynaptic $R_{\text {in }}$ did not vary significantly. This was facilitated by the fact that pectoralis muscle fibers tend to be quite uniform in size. Many of the fibers studied in each muscle could be subdivided into one or two different groups, within each of which the input resistance differed by less than 0.1 megohm. In most cases, it was possible to do this while taking advantage of gaps in the distribution of input resistances in the sampled population. In other cases, where no such gaps existed over a range of 0.2 megohm or more, separate groups were formed arbitrarily. In these cases, alternate groupings were tried, but none were found that contradicted the conclusions presented below. Data from different muscles were not pooled or plotted together because of the different degrees of synaptic block and individual differences in absolute release levels that would have added much variability to the analysis.

\section{Results}

Numbers and locations of junctions. The pectoralis preparation is similar to other frog muscles studied in showing an inverse relationship between nerve terminal length and muscle fiber input resistance. Figure 1 shows 


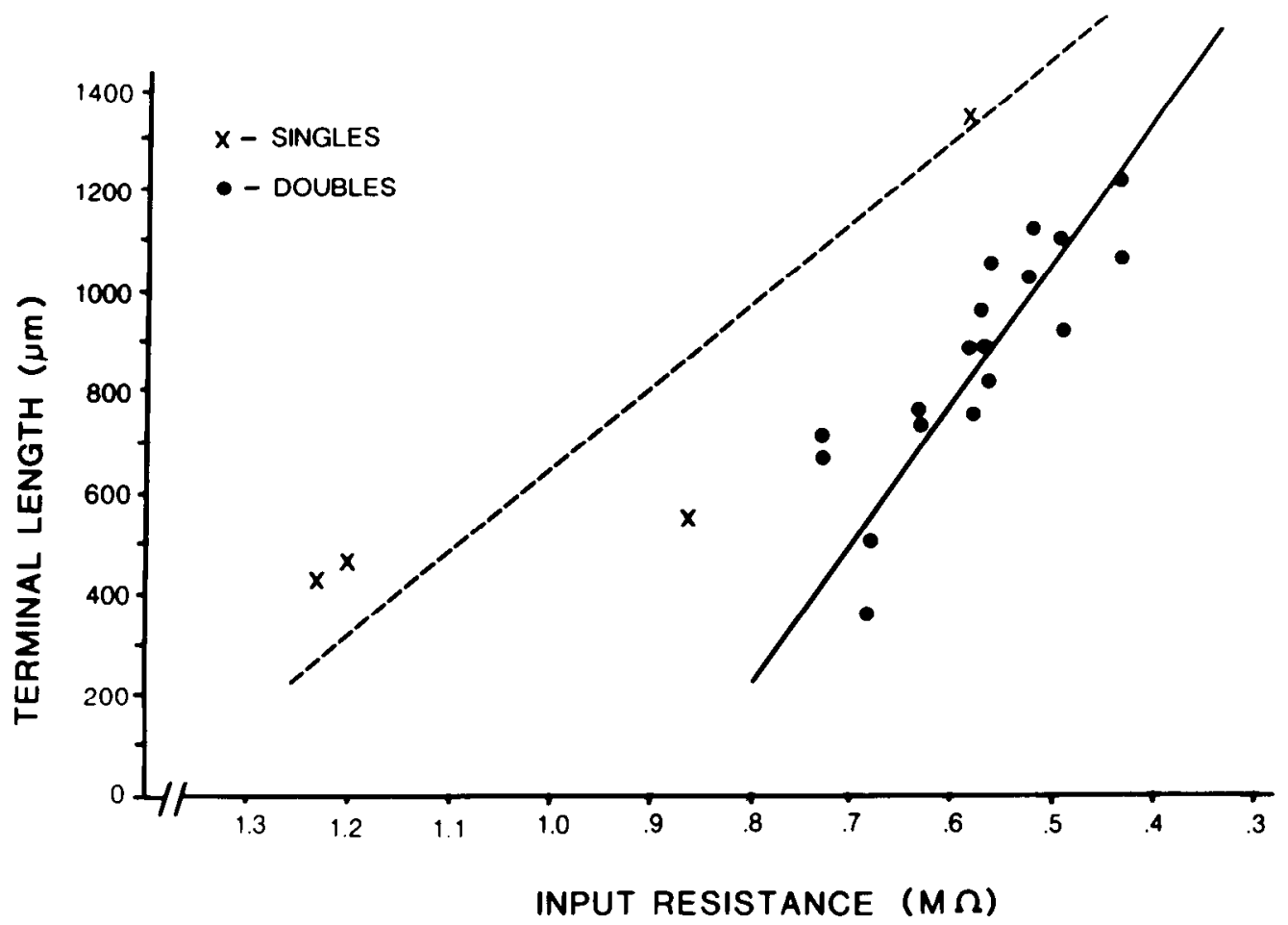

Figure 1. Plot of terminal length vs. fiber input resistance for junctions on nine dually and four singly innervated fibers selected at random from one pectoralis muscle.

characteristic measurements taken from nine dually and four singly innervated fibers in one muscle. This relationship reflects a functional matching between nerve terminals and the fibers they innervate. Figure 1 also reveals two other interesting features of the innervation pattern: (a) there appear to be many more doubly innervated than singly innervated fibers in the part of the muscle studied, and $(b)$ the junctions on singly innervated fibers appear to constitute a separate population in which the terminals are larger for any given $R_{\text {in. }}$.

Figure 2A shows the incidence of singly innervated fibers in pectoralis muscles of different sizes. There was a marked decrease in the percentage of singly innervated fibers with increasing muscle size, from approximately $25 \%$ in muscles having mean fiber lengths of 0.7 to 0.75 $\mathrm{cm}$ (from animals weighing about $10 \mathrm{gm}$ ) to under $5 \%$ in muscles having mean fiber lengths greater than $0.9 \mathrm{~cm}$ (from animals weighing $40 \mathrm{gm}$ or more). Presumably this decrease in proportion of single innervated fibers is a growth-related phenomenon, similar to that reported by Bennett and Pettigrew (1975) in the frog sartorius.

Although Angaut-Petit and Mallart (1979) (see also Haimann et al., 1981a) did not observe a difference between the input resistances of muscle fibers with one or two endplates in their study of this preparation, we found a clear-cut difference. Even in our physiological experiments on identified fibers, where repeated electrode penetrations are needed and relatively large fibers tend to be selected, we found the mean $R_{\text {in }}$ of singly innervated cells to be $0.48 \pm 0.2$ megohm $(N=14)$ and that of dually innervated cells to be $0.38 \pm 0.15$ megohm ( $N=76)(p<0.05, t$ test). When we included the data from another preparation in which fiber $R_{\text {in }}$ was the only physiological parameter obtained, we found even greater differences in mean $R_{\text {in }}(0.59 \pm 0.3$ megohm for singly innervated $(N=18)$ and $0.4 \pm 0.2$ megohm $(N=88)$ for dually innervated fibers $(p<0.01, t$ test)). This led us to suspect that perhaps neither we nor Mallart and his colleagues were sampling the true population of singly innervated fibers during physiological experiments. To obtain a better idea of the relationship between junction number and muscle fiber size, we examined large numbers of dissected fibers from small muscles, with a high incidence of singly innervated fibers. Figure $2 B$ shows data from one such preparation. While there was overlap in the range of fiber diameters exhibited by singly and doubly innervated fibers, their distributions clearly were shifted relative to one another. It should be emphasized, however, that singly innervated fibers occasionally were found with low $R_{\text {in, }}$ and the incidence of single junctions did not decline to zero even in the largest muscles we studied.

When the location of the endplate on these singly innervated fibers was compared with that of the junctions on doubly innervated fibers, it was found that their distributions were conspicuously different. Figure 3 shows the mean location ( $\pm \mathrm{SD}$ ) of the single, double, and the few triple endplates that we found, normalized for muscle fiber length, in randomly selected fibers from nine muscles of 0.7 to $1.2 \mathrm{~cm}$ length. While single junctions were clearly more centered than either the medial or lateral endplates of dually innervated fibers, we often observed overlap between the ranges of single and multiple endplates. This is evident in Figure 4, which shows the exact locations of endplates on fibers of four different muscles representative of the size range studied. In none of the nine experiments did we find any endplates on singly innervated fibers to be on the tendon sides of the 


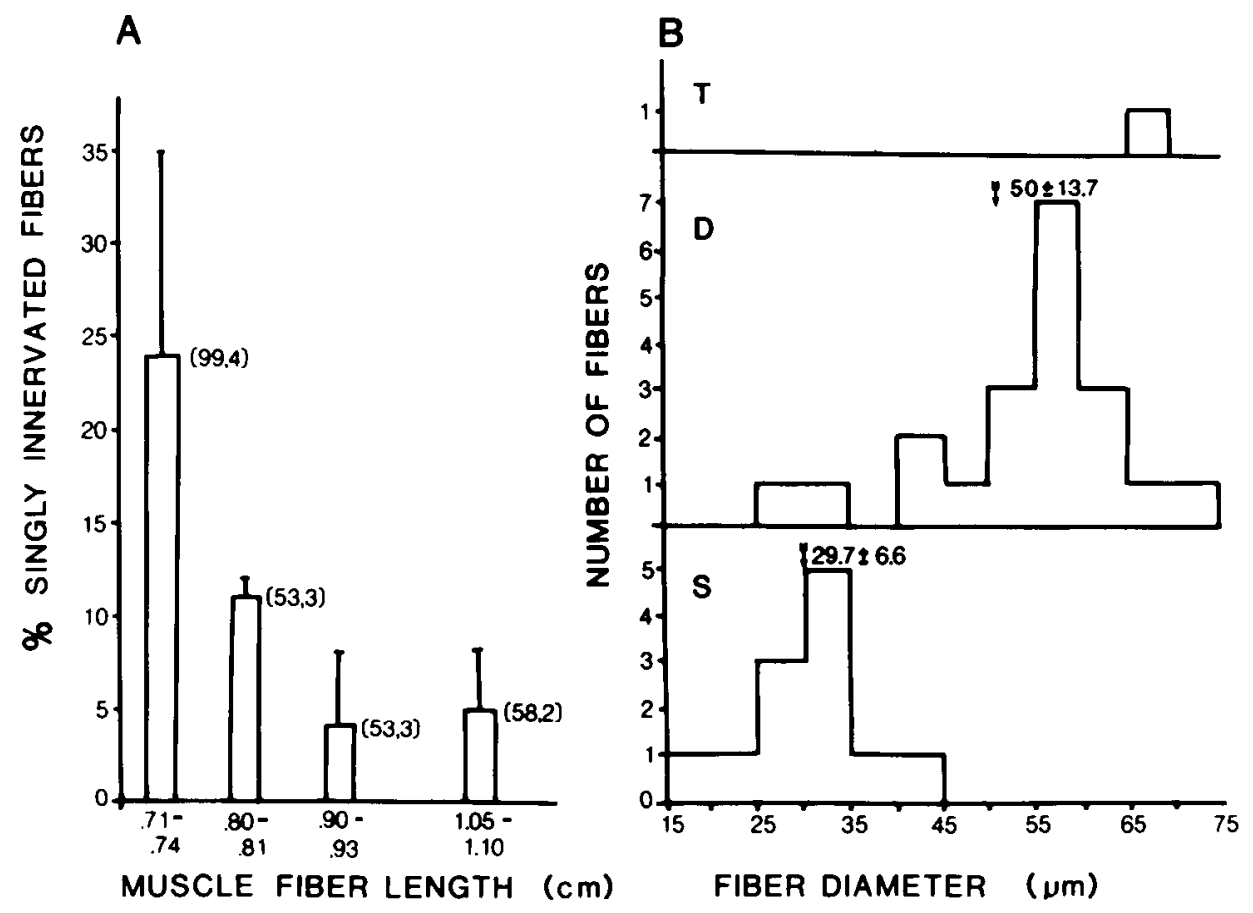

Figure 2. A, Histogram describing the incidence of muscle fibers with one endplate as a function of the mean fiber length of 12 pectoralis preparations. This range of mean muscle fiber lengths represents a large range in animal size. The muscle fibers in the smallest group $(0.71$ to $0.74 \mathrm{~cm})$ came from animals which weighed about $10 \mathrm{gm}$, whereas those of 1.05 to $1.1 \mathrm{~cm}$ came from animals which weighed over $40 \mathrm{gm}$. Error bars represent the standard deviation. The number of muscle fibers and muscles are shown in parentheses. $B$, The data from one muscle which shows the diameters of fibers with one $(S ; N=12)$, two $(D ; N=20)$, or three $(T ; N=1)$ endplates. The mean values $( \pm \mathrm{SD})$ for each group are shown.

mean medial or mean lateral endplate positions of dually innervated fibers.

A significant feature of the distribution of synapses that is not evident from Figures 3 and 4 is the observation that the junctions on dually innervated fibers were never found close together. None were within $10 \%$ of the length of the fiber from each other, and only about $7 \%$ were within $20 \%$ of each other. The mean separation was $31 \%$ of the fiber length $(N=122)$. This distribution is shown in Figure 5. Apparently there is some influence acting to ensure a minimum separation between these paired junctions, a conclusion reached by Bennett and Pettigrew (1975) in their study of synaptic spacing in the developing frog sartorius. It is noteworthy, also, that no junctions were found within $20 \%$ of either end of the fiber. Whether this represents a spatial restriction is not known. It might simply reflect a tendency for fibers to grow at their tendon ends (Griffin et al., 1971), or it may imply that each terminal requires feedback from a large percentage of the length of the fiber.

It is appropriate to ask: what is the functional advantage of having a second junction on a fiber or a centrally placed single junction? It has been suggested that multiple endplates might ensure more simultaneous activation of the whole length of the muscle fiber, thereby increasing the rate or peak tension of a contraction (Katz and Kuffler, 1941). To test this hypothesis we compared the contractions of single fibers when action potentials were initiated by intracellular current injection through floating microelectrodes at single locations or simultaneously at two locations approximating those of the endplates in dually innervated fibers. In 20 pectoralis lateral

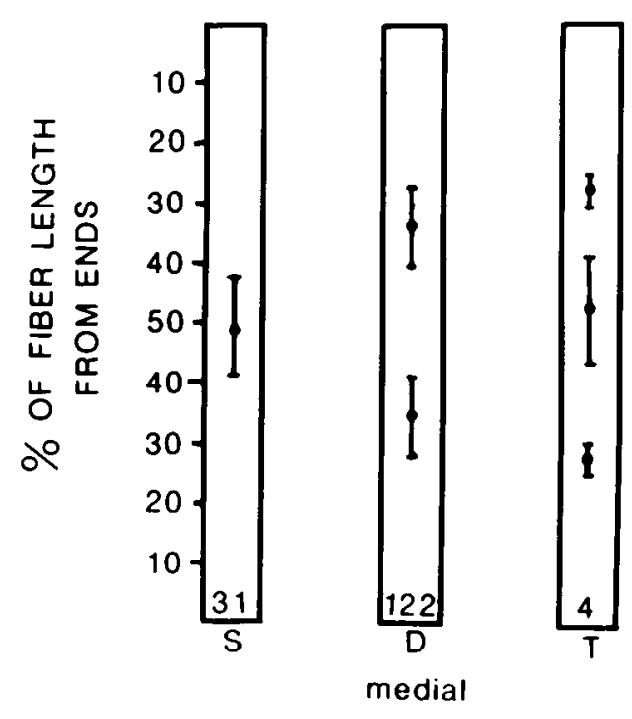

Figure 3. Summary of the mean endplate positions ( $\pm \mathrm{SD}$ ), expressed as the percentage of the total fiber length from lateral and medial ends, of singly $(S ; N=31)$, doubly $(D ; N=122)$, or triply $(T ; N=4)$ innervated fibers. In the case of singly innervated fibers the endplate position was taken to be the mean distance of these endplates from the medial fiber border.

fibers so examined, we could detect no differences in twitch contraction time or magnitude whether an action potential was initiated near the center of the fiber or near one of the tendons. Similarly, no acceleration or enhancement of contraction was seen with simultaneous 
activation at two sites. We conclude, therefore, that in muscle fibers of the size studied in these experiments, there is no obvious functional advantage to dual innervation or central placement of single endplates in terms of contraction speed or magnitude. (On the other hand, there should in theory be some reduction in contraction time resulting from simultaneous activation at different points in longer fibers, and just detectable effects have been seen in large frog sartorius fibers, using similar techniques (L. Trussell and A. Grinnell, unpublished observations)).

Axonal source of dual innervation. In a separate series of experiments with 56 dually innervated fibers (six muscles), we found that $48 \%$ of the fibers were clearly innervated by different axons (either from the anterior or posterior nerves) at the two endplates. We cannot be certain that in the other $52 \%$ of the fibers the same axon
MUSCLE $1(.73 \mathrm{~cm})$

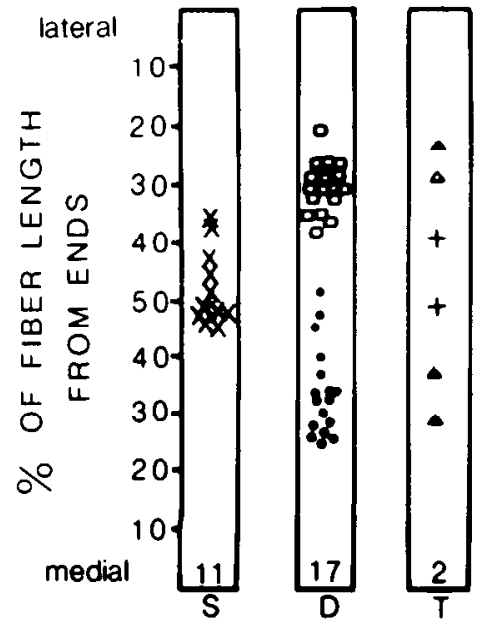

MUSCLE $3(.81 \mathrm{~cm})$

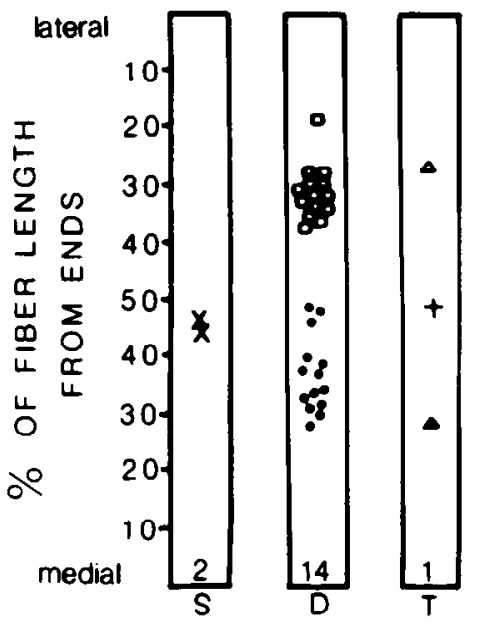

MUSCLE $2(.71 \mathrm{~cm})$

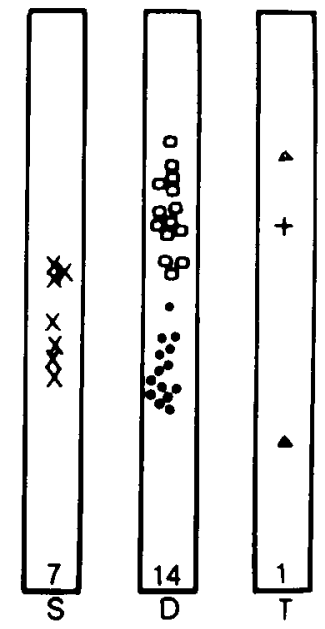

MUSCLE $4(.92 \mathrm{~cm})$

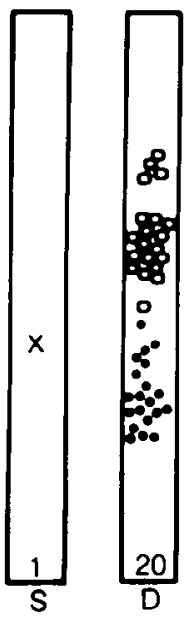

Figure 4. The endplate positions in four muscles of varying mean fiber length. $S, D$, and $T$ correspond to fibers with one, two, or three endplates, respectively. Endplate positions are expressed as the percentage of the total fiber length from either the medial or lateral tendonous insertions. The numbers of fibers in each category are indicated at the base of each bar. $X$, single junction; and $\Pi$, lateral and medial junctions on dually innervated fibers; $\boldsymbol{\Delta},+$, and $\Delta$, junctions on triply innervated fibers.

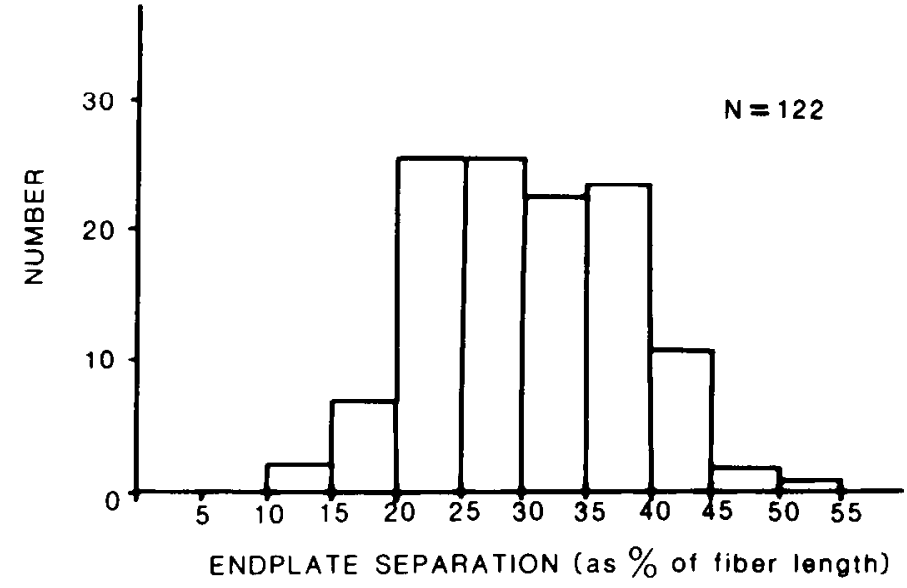

Figure 5. Histogram of the separation between endplates on 122 dually innervated fibers (expressed as the percentage of the fiber's total length).

innervated both endplates, but it was likely that this was so in a high proportion of these, since the EPPs at both sites appeared and disappeared synchronously in random fluctuations at threshold (see "Materials and Methods"). This is probably a much higher proportion than would be expected by random innervation, since the pectoralis muscle is reported to contain approximately 50 motor units (Haimann et al., 1981a). This result is consistent with the unpublished observation of R. Miledi (personal communication) that a majority of fibers in the frog sartorius are innervated at different sites by the same axon.

Size and strength of junctions on doubly innervated fibers. Early in this study we were also struck by the fact that terminals on the same fiber were often very similar in length. In a typical experiment, for example, the four fibers falling in one $R_{\text {in }}$ category had terminal lengths of 630 and $635 \mu \mathrm{m}, 940$ and $810 \mu \mathrm{m}, 918$ and $897 \mu \mathrm{m}$, and 1175 and $1175 \mu \mathrm{m}$ (see Figs. 9 and 10). The dashed line in Figure 6 shows the degree of similarity in length exhibited by terminals on the same fiber in all fibers studied (108 fibers, 18 muscles). Approximately $65 \%$ of the terminals on dually innervated fibers were within $20 \%$ of the length of the other terminal on the same fiber, even though junctions on different fibers of the same $R_{\text {in }}$ could differ by more than $100 \%$. For comparison, the solid line in Figure 6 shows the degree of similarity in length seen between terminals on different dually innervated fibers of equivalent $R_{\text {in }}$ in the same experiments (399 comparisons in 15 muscles, with each junction compared to all other junctions on different fibers of the same $R_{\text {in }}$ in the same experiment only). These curves are clearly different ( $p<0.005, \chi^{2}$ test). We conclude that in dually innervated fibers some regulatory mechanism operating at the level of the individual muscle fiber tends to equalize terminal length at the two junctions. In 43 identified fibers for which axonal origin was determined (data not shown), the similarity in length of the two endplates on the same fiber was no different in those instances $(N=23)$ in which different axons formed the two junctions than when both appeared to be formed by the same axon $(N=20)$, and both distributions were 


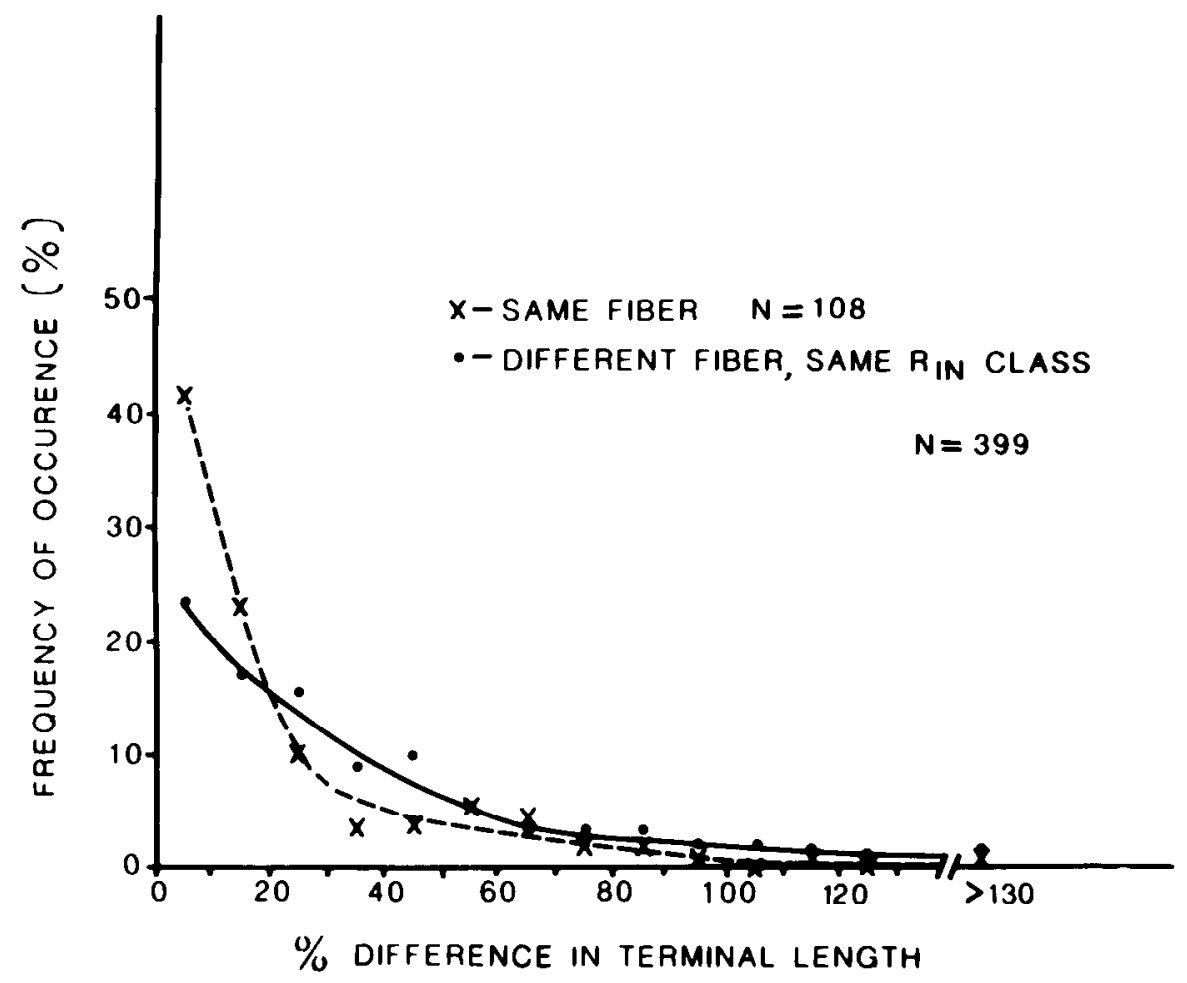

Figure 6. Degree of similarity of terminal length in comparisons of terminals on the same fiber ( $X ; N=108$ fibers) and comparisons between terminals on different doubly innervated fibers of equivalent $R_{\text {in }}$ from the same experiment $(\mathbf{O}$; $N=399$ comparisons). Each point represents the percentage of comparisons falling with a $10 \%$ bin.

indistinguishable from that shown by the solid line in Figure 6.

On the other hand, while terminals on the same fiber usually are similar in size, we have confirmed the observation of Haimann et al. (1981a) that they can differ markedly in physiological strength (see also Ridge and Thompson, 1980, for comparable findings in a Xenopus foot muscle). For the fibers whose terminal lengths were cited above, for example, the pairs of junctions on the four fibers evoked EPPs of 14 and $12.6 \mathrm{mV}, 15.2$ and 6.4 $\mathrm{mV}, 17.6$ and $3.1 \mathrm{mV}$, and 11 and $3 \mathrm{mV}$, in the order cited. Figure 7 plots the ratio of EPP amplitudes for pairs of junctions in the same fiber vs. the percentage difference in length of their terminals. The EPP amplitudes in these cases were corrected only for resting potential. A plot of quantal contents or EPPs corrected for nonlinear summation would show greater variation. Figure 7 shows that terminals on the same fiber which differ by less than $10 \%$ in length can vary by as much as $500 \%$ in EPP amplitude. It is of interest to ask whether there is any significant tendency for the two junctions on a given fiber to be of equal strength. Figure 8 shows the degrees of similarity in EPP amplitude (corrected only for resting potential) when junctions were compared on the same dually innervated fiber or to junctions on different dually innervated fibers in the same experiment, regardless of $R_{\text {in. }}$. Apparently there is no greater tendency for the two junctions on a given fiber to be of similar strength than for any two junctions on different fibers. This was also found to be the case for the smaller subpopulation of junctions on dually innervated fibers of equivalent $R_{\text {in }}$.

Other variables that could possibly govern the strength of two junctions on a fiber did not seem to be important. For example, the two endplates derive from medial and lateral branches of each nerve. One of these branches may normally develop first, so that endplates formed by it might have an advantage and be expected to be stronger or consistently different in size. In fact, the stronger junction was on the lateral side in 39 fibers and was on the medial side in 36 fibers. Similarly, the stronger junction was longer than the weaker in 39 cases and was smaller in 36. Also, there was no apparent correlation between average EPP amplitude or terminal length and the distance separating endplates on dually innervated fibers.

From these data and Figure 7, it is not surprising that simple plots of release per unit terminal length vs. terminal length for terminals on fibers of equivalent input resistance, which revealed an orderly inverse relationship in the singly innervated $R$. pipiens cutaneous pectoris muscle fibers (Nudell and Grinnell, 1982), would not yield a meaningful relationship in the case of the pectoralis muscle. Suspecting that there may be some orderly relationship between terminal size and strength in dually innervated fibers, however, we have examined the data for any form of consistent correlation. Within several input resistance groups there was a clear-cut inverse relationship between the length of the stronger junction and its release per unit length. However, this was sometimes not the case (see below), and the weaker junctions not only fell entirely outside this relationship, but normally showed no correlation between length and release among themselves. On the other hand, in all input resistance groups examined (15 groups in 12 muscles), there 


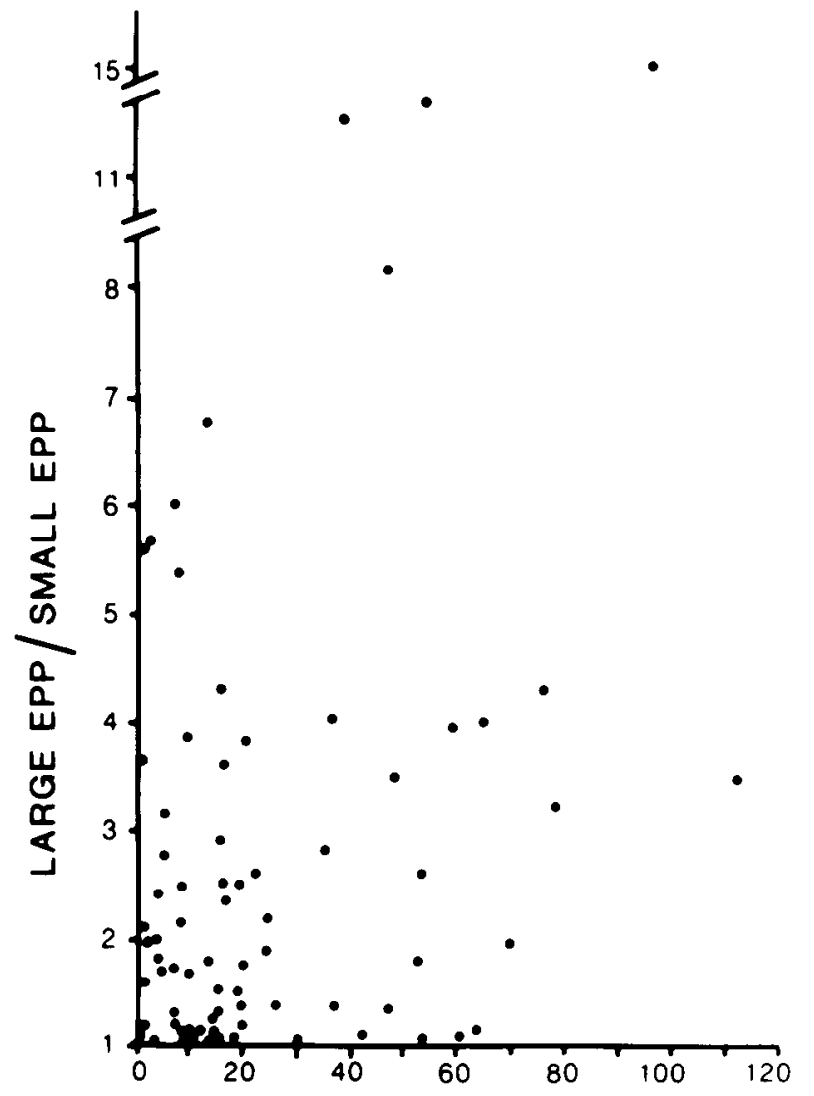

\% Difference in terminal LenGth

Figure 7. Plot of the ratio of EPP sizes of endplates on the same fiber vs. the percentage difference in their length for 74 fibers in 14 muscles. The percentage difference in length was defined as (longer/shorter -1$) \times 100 \%$. was a convincing inverse linear relationship between the mean release per unit length or total release of both terminals on a fiber and the summed length of both terminals. Figure 9 shows several examples of the relationship between mean release per unit length and summed terminal length. Two symbols are used in several graphs. The solid circles represent data taken from dually innervated fibers whose individual terminal lengths differed by less than $20 \%$. The $X$ 's represent data from fibers with terminals differing by more than $20 \%$ in length. The lines show the best fit for all fibers in each input resistance group. It is apparent that in some $R_{\text {in }}$ groups (e.g., Fig. $9, D, F$, and $H$ ) the correlation between release and total length is better for that majority of cases in which the two terminals on each fiber were of approximately the same length than when fibers are included in which the lengths differed by more than $20 \%$, although the latter still conformed to the general inverse relationship between release and length. In view of the striking similarity in terminal lengths on most fibers, we feel that there is some justification for treating these fibers as a population expressing some form of stable regulation of terminal size and strength. The fibers with terminals of disparate length may not belong to the same population. In particular, they may reflect a different developmental history. For instance, these may be fibers in which a second endplate had been added at a relatively late developmental stage (cf. Fig. $2 A$ ). If this is the case, the developmentally younger endplates might have had less opportunity to influence the growth and release properties of the larger, presumably older synapses. It might be expected, therefore, that some cells in this category would not fit nicely into the curves relating average synaptic strength and total terminal length for cells whose terminals are very similar in size.

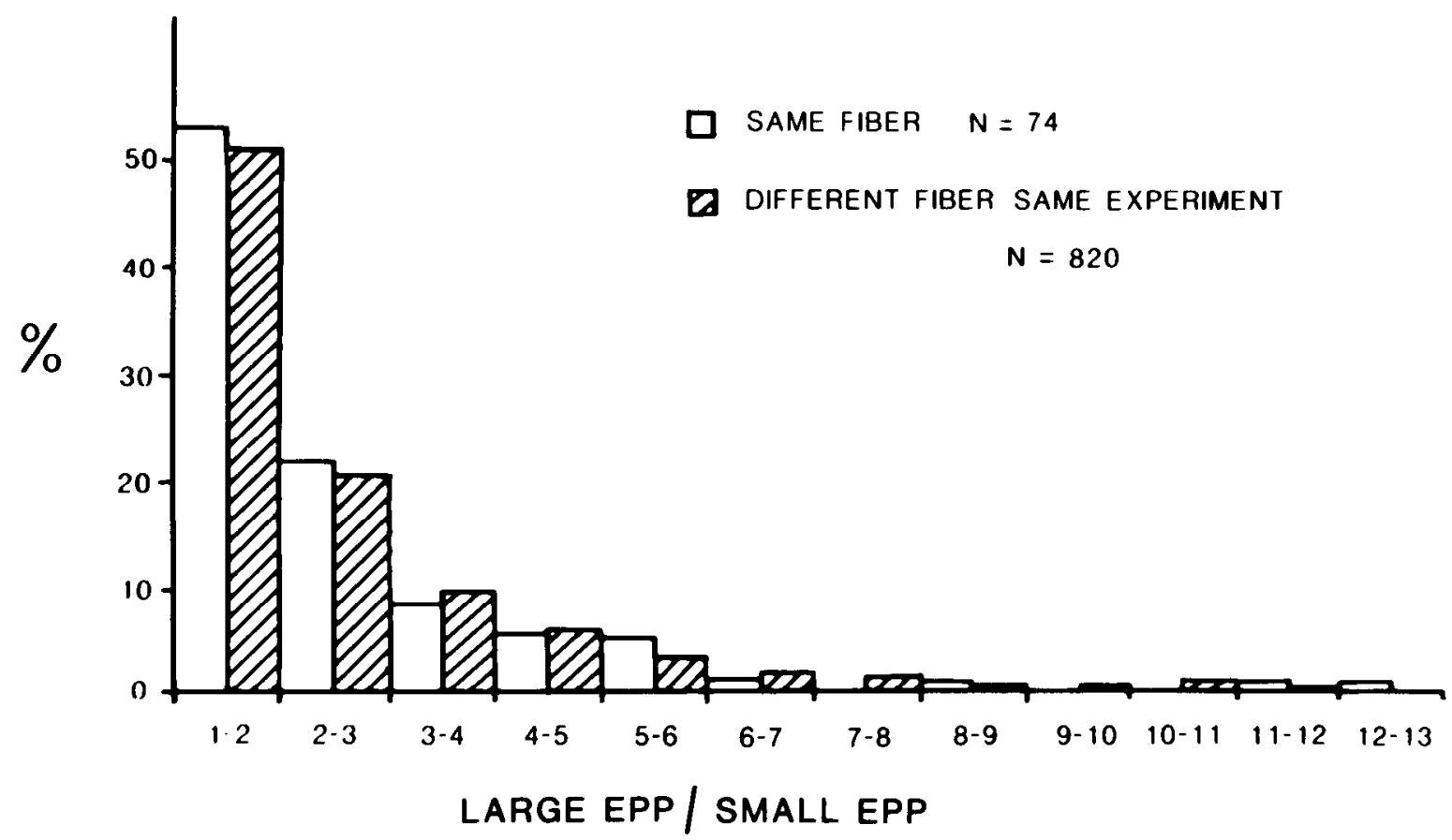

Figure 8. Histogram showing the degree of similarity in EPP size (corrected for resting potential) seen between junctions on the same dually innervated fiber $(\square ; N=74)$ and between endplates on different dually innervated fibers in the same experiment (圈; $N=820$ ). 

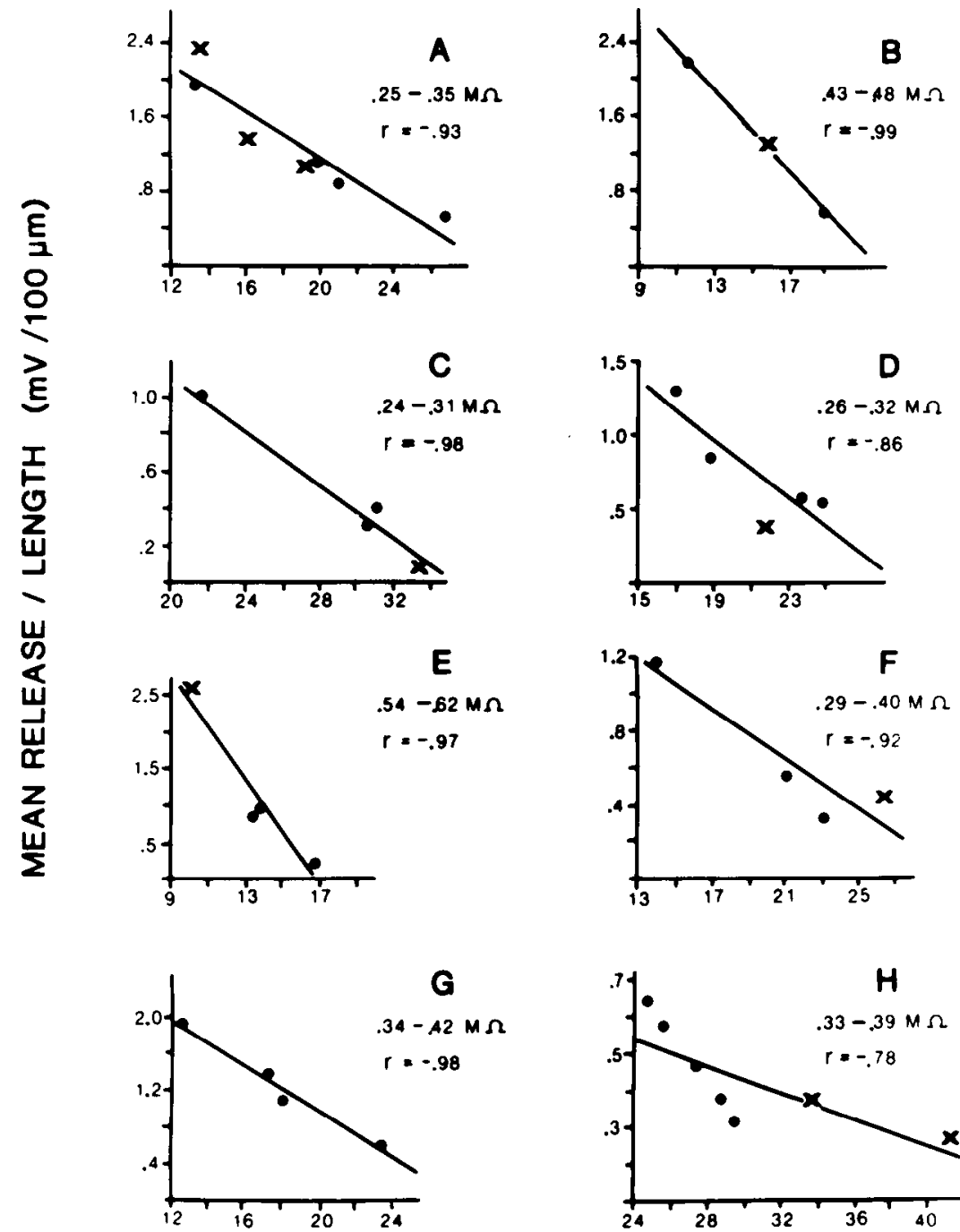

\section{TOTAL TERMINAL LENGTH ( $x 100 \mu \mathrm{m})$}

Figure 9. Mean release $/ 100 \mu \mathrm{m}$ terminal length vs. total terminal length for eight $R_{\text {in }}$ groups of dually innervated fibers in seven muscles. $E$ and $F$ are from the same muscle. EPPs were corrected for resting potential and normalized to the mean input resistance of each group. Data for those cells whose terminals differ by $20 \%$ or less in length are represented by solid circles, and cells whose terminals differed by more than $20 \%$ are depicted by $X^{\prime}$ 's. Also shown are the range in $R_{\text {in }}$ and the correlation coefficient for the line of best fit for all of the fibers in each group.

From the endpoints of the lines of best fit, determined by the mean terminal length at the minimum and maximum release values observed for the eight groups shown in Figure 9, as well as the other seven groups (not shown), we found that, for dually innervated cells of equivalent $R_{\text {in, a }} 78 \%$ greater total terminal length was correlated with $72 \%$ lower average release per unit length. For the two singly innervated $R_{\text {in }}$ groups found (data not shown) $44 \%$ greater length was correlated with $62 \%$ lower release per unit length. Figure 10 is another plot of data from the same $R_{\text {in }}$ groups as those in Figure 9, but now correlating total release (summed EPP amplitudes for both terminals, each corrected for resting potential and $R_{\text {in }}$ ) with total terminal length. It is clear that the greater length of longer terminals does not fully compensate for their relative deficits in release per unit length. The fibers with shorter terminals received absolutely greater amounts of transmitter, in inverse proportion to their summed terminal lengths.

Summarizing these data, the mean ratio of the longest/ shortest summed terminal lengths for the 15 dually innervated $R_{\text {in }}$ groups was $1.65 \pm 0.34$. The mean ratio of the EPPs of the longest/shortest terminal pairs, both corrected for resting potential, was $0.42 \pm 0.24$. Using EPPs corrected for nonlinear summation would further reduce the latter ratio. The corresponding figures for two $R_{\text {in }}$ groups of singly innervated fibers were 1.44 (long/ short terminal lengths) and 0.53 (long/short EPP, corrected for resting potential).

As mentioned above, attempts were made to find other or better ways of correlating terminal length with junctional physiological properties. Since action potential initiation at any site along the length of the fibers appears to be functionally equivalent to simultaneous action po- 

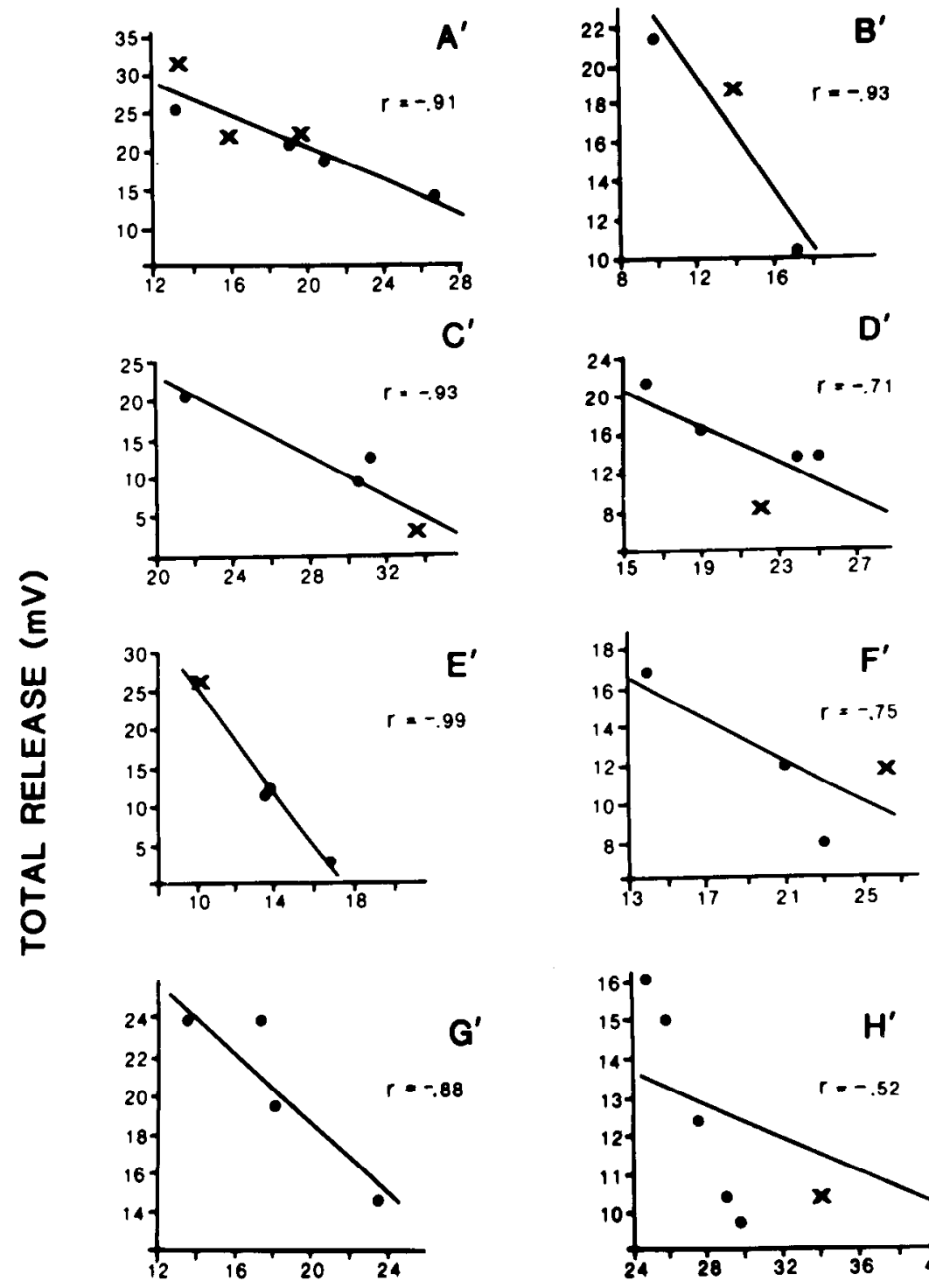

\section{TOTAL TERMINAL LENGTH ( $\times 100 \mu \mathrm{m})$}

Figure 10. The sum of the EPPs evoked at both endplates on dually innervated fibers vs. total terminal length for the same $R_{\text {in }}$ groups depicted in Figure 9. EPPs were corrected for resting potential and normalized to the mean $R_{\text {in }}$ value in the group. Correlation coefficients for the lines of best fit are shown for each group.

tential initiation at two well separated sites (see above), one possibility is that the total terminal length on a fiber is regulated by the strength of the stronger junction alone. To examine this possibility, the release per unit length and total release of the strongest junction on dually innervated fibers were plotted against the summed length of both endplates. Cases in which the stronger terminals on fibers of the same $R_{\text {in }}$ are roughly equivalent in strength but in which the less powerful of the junctions on each fiber are very different in their strength should provide the best test of this correlation. We have found three such cases, in all of which plots of the EPP amplitude (and to a less dramatic extent, the release per unit length) of the strongest junction vs. total terminal length yielded a less convincing correlation than mean release of both junctions.
Properties of junctions of disparate size on dually innervated fibers. It must be emphasized that the correlation between release and total terminal length is degraded significantly in some cases when fibers having terminals which differed by more than $20 \%$ in length are included in the analysis (cf. Figs. 9 and 10). It is of obvious interest to characterize more explicitly the disparately sized terminals on those fibers whose endplates did not seem to follow the same rules as do fibers with junctions of similar length.

In most cases (but not all) the longer of the two terminals of disparate length was characterized by lower release per unit length and lower EPP values than the mean of all the junctions in the experiment. In 13 cases, comparisons could be made between fibers with disparately sized junctions and more typical fibers in the same 
$R_{\text {in }}$ group. Seven of these fibers were characterized by having one extraordinarily long terminal, which was $43 \%$ longer, on the average, than the longest terminal on the other fibers. Four of these seven had second terminals that were also relatively long, exceeding the mean terminal length of the junctions on the other fibers in the group. These four deviated conspicuously from the relationship between release and total length that was characteristic of the fibers having both junctions of similar length. Three of these are included in the examples of Figs. $9, F$ and $H$, and $10, F^{\prime}$ and $H^{\prime}$, from which it is clear that their terminals were larger than would be predicted from their levels of release. Of the remaining six fibers that had terminals of disparate length, but neither unusually long, only one fiber deviated sharply from the pattern of others in the $R_{\text {in }}$ group, and its terminals released somewhat less transmitter than would have been expected on the basis of the other fibers in the group (Figs. $9 D$ and $10 D^{\prime}$ ).

Size and strength of terminals on singly innervated fibers. In confirmation of the findings of Haimann et al. (1981a), we have found that the junctions on singly innervated fibers are, on the average, stronger than the junctions on dually innervated fibers. Eleven singly innervated fibers could be compared with dually innervated fibers of equivalent $R_{\text {in }}$ in the same experiment in 10 muscles, for a total of 23 individual comparisons. Single junctions produced a larger EPP than the sum of the two junctional EPPs on dually innervated fibers in 15 cases, while their EPPs were less than the combined total in 8 comparisons. In those 8 , however, the solitary junction was stronger than either junction alone on the dually innervated fiber in 4 comparisons. The mean ratio of the single junction's EPP/summed EPPs of the two junctions on all of the dually innervated fibers within the same $R_{\text {in }}$ group was $1.58 \pm 1.11(N=23)$. The single endplates were, on the average, 0.58 times the combined length of the double endplates. Thus, given the strength of the single junction EPPs we observed, it follows that the mean release per unit length was much greater $(2.63 \pm$ 2.08 times) in single junction terminals than in those from dually innervated fibers of the same $R_{\mathrm{in}}$.

Although most single junctions found were strong compared with the junctions on dually innervated fibers of the same $R_{\text {in }}$, it is important to note that in each experiment most dually innervated fibers were of larger diameter (lower $R_{\text {in }}$ ) (see Fig. $2 B$ ), and in many of these fibers one or both junctions had bigger EPPs than the single junctions. If one compares the average EPP amplitude, corrected only for resting potential, for all single junctions studied $(N=14)$ with the summed EPPs of all dually innervated fibers within each experiment, regardless of $R_{\text {in }}(N=47)$, the ratio was 0.86 .

\section{Discussion}

The principal findings of this paper are that: $(a)$ with increasing muscle size, an increasing proportion of the muscle fibers become dually innervated, probably as a result of normal maturation processes. (b) The remaining singly innervated fibers have junctions that are somewhat longer, and much stronger, than most junctions on dually innervated fibers of the same input resistance.
Moreover, the single junctions are located close to the middle of the fibers, while the two junctions on dually innervated fibers are located to either side and are always well separated from one another. (c) The paired junctions on a dually innervated fiber tend to be much more similar in length than junctions on different fibers of the same $R_{\text {in }}$ group. There is no corresponding tendency for both junctions on a given fiber to be of similar strength (EPP amplitude). (d) A high proportion (approximately 50\%) of dually innervated fibers appear to be innervated at both sites by the same axon. (e) The length of the junctions on dually innervated fibers is inversely proportional to the total release of transmitter from both terminals and the $R_{\text {in }}$ of the fiber. The correlation between length and strength for either of the pair considered alone is relatively poor. Taken together, these observations imply the existence of several interacting influences that help govern the morphology and physiology of junctions in this muscle. Although rigorous answers at the mechanistic level are still elusive, considerable insight has been gained into the following processes.

1. The regulation of synaptic length. The two nerve terminals on dually innervated fibers tend to be of similar length, although they may differ by severalfold in their EPP amplitudes, and other fibers in the same $R_{\text {in }}$ category may have terminals of very different mean length and strength. Thus some property of each fiber, uniformly expressed along its length, appears to be governing synaptic growth and total length. A key finding in the present study is that the muscle fiber property that regulates terminal length is itself correlated with the mean or total strength of these junctions, not the properties of either junction alone. There is no apparent tendency for the stronger of the two terminals to be longer or shorter than the weaker. Synaptic input is not the only correlate of terminal length, however. The size of the muscle fiber is also important. As fibers grow and their $R_{\text {in }}$ decreases, a given EPP amplitude requires greater transmitter release and is correlated with progressively longer terminals. One explanation of our findings is that the combined synaptic input acts to modulate the amount of a growth-promoting stimulus that is synthesized by muscle fibers in proportion to their size (volume). A certain amount of this substance may be required to maintain a corresponding length of terminal. If more is available than is necessary to maintain the existent length, perhaps because of fiber growth, the terminal might grow to an appropriate length for the amount supplied or another axon terminal might be accepted. If there is a decline in the amount of growthpromoting factor available, for example, because a strong second terminal has appeared, reducing the overall level of synthesis of the substance and/or inactivating or depleting it, a long terminal might shrink. A mechanism of this sort could explain the dynamic equilibrium that appears to exist at normal frog junctions, characterized by both elongation and retraction of terminal branches as a function of seasonal or other factors (Bennett and Pettigrew, 1975; Wernig et al., 1980; Herrera and Grinnell, 1981).

Comparable models of regulation have been postulated before, on the basis of other lines of evidence. Since the 
work of Hoffman (1951), it has been thought that denervated fibers may produce a sprout-inducing substance. More recently, it has been shown that both partially denervated and paralyzed muscles induce nerve terminal sprouting and synapse formation (see review by Brown et al., 1981). Conversely, there is competition between active junctions on muscle fibers, resulting in synapse elimination during early postnatal development, and elimination of supernumerary synapses on adult fibers (see reviews by Lømo and Jansen, 1980; Grinnell and Herrera, 1981). This competition can take place up to a few millimeters distance (implying interaction via the muscle fibers) but apparently not further away (Frank et al., 1975; Bennett and Pettigrew, 1975; Brown et al., 1976; Kuffler et al., 1977, 1980; Grinnell et al., 1977, 1979; Haimann et al., 1976, $1981 \mathrm{a}, \mathrm{b})$. On the basis of these findings, Jansen and his colleagues (Jansen et al., 1978; Kuffler et al., 1980; Lømo and Jansen, 1980) have suggested that muscle fibers produce a substance that induces sprouting and synapse formation, the amount of which varies inversely with the level of muscle fiber activity. To explain synapse elimination, Jansen and his collaborators postulate that the substance is produced in limited quantities and that nerve terminals can deplete the substance from surrounding regions of the fiber (see also Purves, 1976, for a history of the development of this idea). A similar scheme is implied by the results of Diamond and his collaborators for skin sensory connections in salamanders (Diamond et al., 1976; Cooper et al., 1977; Diamond, 1979). The Merkle cells in the skin produce a sprout-inducing or sensory nerve-attracting substance that is suppressed or removed by innervating sensory nerves (Purves, 1976; Diamond, 1979).

In the present experiments, it would appear that the modulatory influence of the combined synaptic input is somehow distributed evenly throughout the muscle fiber, so that terminals tend to be the same length whether both are of the same strength or differ by manyfold in strength. How can the synaptic influences be summed throughout the fiber and expressed equally? The activity patern of the muscle fiber is an obvious and attractive candidate. One would expect its effect to be equally expressed throughout a fiber, and a mechanism of regulation based on muscle fiber activity would seem to provide the most relevant information; that is, is the terminal successful in evoking activity, and at what level? Moreover, it is well known that directly imposed activity can largely reverse the postsynaptic effects of denervation (Lømo and Rosenthal, 1972; Drachman and Witzke, 1972; Lømo et al., 1974; Lømo and Westgaard, 1975; Lømo, 1976; Fambrough, 1979), as well as prevent nerve terminal sprouting (Brown and Holland, 1979; Brown et al., 1980) or innervation by a preimplanted foreign nerve (Jansen et al., 1973). Synapse elimination is delayed by partial denervation (Thompson and Jansen, 1977; Betz et al., 1980a) and accelerated by nerve stimulation (O'Brien et al., 1978).

We have no information regarding activity levels in different pectoralis fibers or how this is correlated with terminal length. It is quite possible that a weak terminal, even coupled with a very stong one, could contribute importantly to the fiber's total activity, depending on the safety margin of each, the pattern, frequency, and asynchrony of firing of the two terminals, and the degrees of facilitation and depression of each at normally occurring firing frequencies. Perhaps terminals are induced to grow until the muscle fiber activity they evoke by their combined suprathreshold inputs reduces the level of growthpromoting stimulus to a level that stops further growth. However, two lines of evidence make it difficult to explain the relationship between summed synaptic strength and total terminal length on the basis of muscle fiber activity. In the first place, it would seem necessary to assume that the contribution of each terminal to the overall muscle fiber activity is proportional to the amount of transmitter released by each, despite the fact that action potential initiation is a threshold phenomenon. Secondly, both junctions in a significant proportion of fibers are formed by the same axon. The activity patterns of these muscle fibers presumably are no different than if they had been innervated at only one location, yet the summed synaptic output still is an accurate predictor of terminal length.

An alternative interpretation of our basic finding is that ACh or some as yet unidentified trophic substance released with $\mathrm{ACh}$, either directly or via a second messenger in the muscle fiber, is responsible for limiting the fiber-wide production of terminal growth factor(s). Our measurements of the release elicited in response to a few stimuli at $1 \mathrm{~Hz}$ undoubtedly do not reflect quantitatively the output of $\mathrm{ACh}$ (or putative trophic substance) that each fiber sees in vivo. Especially if high frequency trains of nerve impulses are characteristic of normal activity, weaker junctions may be relatively more important, because of their greater facilitation and reduced synaptic depression (Nudell and Grinnell, 1982). Also, a significant fraction of the ACh released by a nerve terminal is in the form of nonquantal spontaneous leakage (Katz and Miledi, 1977), the rate of which may or may not be proportional to the terminal's evoked release capabilities. Despite these uncertainties, however, we feel that our data are compatible with a form of regulation depending directly upon the total synaptic release of ACh or some associated trophic factor. Whatever the underlying mechanism(s) may be, the adaptive significance of such a regulatory process might be that it causes paired junctions with relatively low mean release per unit length to compensate for deficits in intrinsic strength by additional terminal growth, thereby assuring that each fiber will have at least one effective synapse. ${ }^{3}$

\footnotetext{
${ }^{3}$ Preliminary findings, based on electron microscopic semiserial reconstruction of several frog sartorius endplates that had been characterized physiologically, suggest that there is a positive correlation between mean release per unit length and the mean cross-sectional width of close apposition between the presynaptic terminal and the subsynaptic: membrane (Herrera and Grinnell, 1982). For a group of five junctions in one muscle, an 8-fold difference in release per unit length was strongly correlated with a difference in apposition width of approximately 1.8 -fold. Whether this correlation will be confirmed by future study remains to be seen. Since we have found that within any given $R_{\text {in }}$ group there is usually about a 2 -fold range of terminal lengths, this ultrastructural correlation raises a possible alternative interpretation of our finding that mean release per unit length is related inversely to total terminal length, namely that total terminal area of apposition might be held constant on fibers of equivalent $R_{\text {in }}$, with release per unit
} 
2. The regulation of synaptic number. Singly innervated fibers tend to be smaller, with higher $R_{\text {in }}$, than most dually innervated fibers. Moreover, the single junctions, at least in those fibers that remain singly innervated into the adult stages we have studied, are always centrally located on their fibers and tend to be longer, with larger EPPs, than either junction on dually innervated fibers. In fact, in most experiments, EPPs from single junctions are stronger than the summed EPPs of double junctions on fibers of the same $R_{\text {in }}$.

With increasing muscle size, the percentage of singly innervated fibers declines. The system behaves as though a muscle fiber has a need for innervation (or generates a stimulus for innervation such as a sprouting factor or the growth-promoting factor postulated above) in proportion to its size, and this need is satisfied (or the innervation stimulus is removed) by a nerve terminal in proportion to its strength. As the fiber increases in size, however, it may be that even a strong terminal becomes increasingly inadequate to satisfy the fiber's requirements. In addition, a nerve terminal is apparently effective in excluding other innervation only over adjacent portions of the membrane (see below). If the junction is relatively weak or is located to one side (either initially or at later developmental stages due to asymmetric fiber growth (see Bennett and Pettigrew, 1975)), the other side of the fiber can escape regulation and attract (or accept) another junction. The least likely fibers to become doubly innervated would then be those that are small and have a strong, centrally located junction. A comparable tendency to add more junctions during development and to maintain a minimum distance between them has been pointed out in the frog sartorius muscle (Bennett and Pettigrew, 1975). Whether addition of a second junction on a pectoralis fiber accelerates muscle fiber growth cannot be resolved from our data but is not inconsistent with it.

3. The regulation of synaptic position on muscle fibers. The junctions on dually innervated fibers are always separated by a significant distancc. Furthermore, the central location of single junctions seemingly contributes to their ability to exclude other junctions from the regions of muscle fiber that typically accept dual endplates (see Figs. 3 and 4). We take these observations to be compelling evidence for some form of short-range exclusionary interaction between junctions. There is widespread evidence for competitive elimination or suppression of one synapse by another in many systems, both during the developmental period of synapse elimination (Brown et al., 1976; Betz et al., 1980a, b; see reviews by Purves and Lichtman, 1980; Grinnell and Herrera, 1981) and in hyperinnervated adult amphibian (Grimm, 1971; Dennis and Yip, 1978; Bennett et al., 1979; Grinnell et al., 1979) and mammalian muscle (McArdle, 1975; Jansen and Van Essen, 1975; Thompson and Jansen, 1977; Brown and

\footnotetext{
length steeply related to apposition width. The same ultrastructural study has shown that light microscopic measurements of terminal width do not reflect accurately the true width of synaptic apposition, since this parameter is dependent on the extent of Schwann cell interposition between the pre- and postsynaptic structures.
}

Ironton, 1978), at least when the junctions are within 1 to $4 \mathrm{~mm}$ of each other (Kuffler et al., 1977, 1980).

The exclusionary interaction between terminals that we observe in Xenopus muscle appears to operate strongly only over a distance of 1 to $3 \mathrm{~mm}$; that is, about 10 to $30 \%$ of the length of the fiber. We do not know the mechanism of interaction responsible, and there are many possibilities. However, our data are compatible with the model suggested by Lømo and Jansen (1980), in which a nerve terminal, in addition to helping to determine the overall fiber-wide synthesis level of a growthpromoting substance, also removes or inactivates the substance in adjacent portions of the membrane. The precise rules governing the spacing of endplates have yet to be determined. In these experiments we did not find a convincing correlation between the distance separating endplates and their synaptic strengths or lengths.

4. The regulation of synaptic strength. We have no explanation for the fact that some nerve terminals release large amounts of transmitter per unit length, while others are very weak, or why one terminal on a fiber may generate a curare-reduced EPP of $15 \mathrm{mV}$, while the other on the same fiber may produce an EPP of only $1.5 \mathrm{mV}$. Presumably this depends on intrinsic properties of the different motor neurons and the size of their peripheral arborizations (Ridge and Thompson, 1980; L. Trussell and A. D. Grinnell, unpublished observation). The results summarized in Figures 7 and 8 are consistent with those of Ridge and Thompson (1980) and Haimann et al. (1981a) in Xenopus muscle but contrast with those of Weakly (1978), who found that the multiple endplates on $R$. pipiens sartorius muscle fibers had EPP amplitudes much more alike than randomly compared junctions in the same muscle. This difference may be attributable to species and/or preparation differences or to the fact that, in our experiments, comparisons have been restricted to fibers with two endplates. As both Angaut-Petit and Mallart (1979) and we have shown, singly innervated fibers have stronger junctions, on the average, than do fibers with multiple endplates. Hence it is likely that random comparison of all junctions in the sartorius, irrespective of the number of endplates on each fiber, would result in more variability than comparisons among fibers with the same number of endplates.

Exceptions and their implications. Not surprisingly, there are exceptions to the "rules" delineated above. Some dually innervated fibers have junctions of disparate length, for example. Even in these instances most pairs of junctions conform approximately to the observed relationship between total release and total terminal length, when compared with other fibers of the same $R_{\text {in }}$. In some cases, however, the deviation is large, especially in the direction of having much longer terminals than expected for the EPP amplitudes observed. There are doubtless many variables involved in determining terminal size and release properties that we have not been able to evaluate, including especially the unknown activity levels of different terminals and fibers and the size of the motor unit to which each belongs. One plausible variable, whether the two junctions formed on a fiber are from the same or different axons, appears not to be important. However, a possible explanation of these 
"deviant" fibers is that they are cases in which a singly innervated fiber had acquired a second endplate at a relatively late developmental stage. This would be consistent with the observation that these fibers typically have one terminal of unusual length. It might previously have been an inadequately strong or asymmetrically placed single junction that lost its ability to maintain exclusive innervation as the fiber increased in size. In most cases these long terminals are significantly longer and have lower levels of release per unit length and smaller EPPs than single junctions in the same experiments. However, it might be anticipated that, if there is a growth-regulating feedback influence from the muscle fiber, it would stimulate the existent terminal to grow longer well before successfully attracting innervation by another axon.

It may be that equivalence of terminal length on the same fiber is an equilibrium state toward which all dually innervated fibers tend. If our hypothesis concerning the origin of disparately sized terminals is correct, absolute differences in terminal length could be minimized by either (1) reduction in length (and consequently strength) of the first junction or (2) differential growth of both as they approximate equality of length. It must be noted that if most fibers and their terminals are relatively small (Fig. $2 B$ ) when a second endplate is added, the equivalent growth of both endplates could result in junctions of relatively equal length upon examination of fibers from older animals.

If the size and strength of junctions on dually innervated fibers are determined in large part by the factors outlined above, then one might expect single junctions to follow the same rules. To a first approximation this is the case. Their length is usually less than the total of even short pairs of dual junctions, and the transmitter output is greater than most in the comparison group. On the other hand, single junctions generally do not fit nicely into the curves that describe the relationship between total release and total length for dual junctions. In some cases, for instance, we find dually innervated cells that receive as much or more transmitter than do singly innervated cells of equivalent input resistance, and yet support greater lengths of terminal than do the singly innervated cells. This implies that the fiber's total potential to support terminal growth is not fully tapped by many single junctions and that there may be spatial limits to the ability of a given terminal to draw on a muscle fiber's growth-promoting factor(s). This is consistent with the finding that most singly innervated fibers do eventually acquire another endplate.

Significance of the second junction on dually innervated fibers. Finally, it is of interest to ask why a second junction is formed on these fibers. Since simultaneous activation of the two junctions does not appear to alter contraction mechanically, it is more likely that the adaptive significance of the second input is to ensure an overlap of different motor units, providing a mechanism for the fine control of muscle tension and perhaps increased resistance to neuromuscular fatigue ( $R$. Rahamimoff, personal communication). However, the high percentage of fibers dually innervated by the same axon, in which the second endplate cannot contribute in any obvious way to the fiber's activity, strongly implies that the second junction can play an important role independent of activity. This finding may have interesting implications for other regulatory phenomena, such as the appearance of extrajunctional $\mathrm{ACh}$ receptors and induction of sprouting following partial denervation or neuromuscular block.

The regulatory processes we infer represent a model for competition in that they act to limit the effectiveness of certain junctions when they co-innervate a fiber with a very strong junction. A terminal of average or subaverage release efficacy coupled with a very strong terminal will not grow as long as if it were coupled with a weaker terminal. In the first case, it might remain subthreshold except at high firing frequencies, while in the latter case it might have a significant safety margin.

It will also be of interest to determine what selective processes are responsible for the high incidence of muscle fibers that are dually innervated by the same axon. Among possible explanations for this pattern of innervation are a tendency toward selection or retention of terminals that are always active synchronously with postsynaptic activity (Stent, 1973) or which do not add to overall muscle fiber activity (Kuffler et al., 1980). It is also possible that the axon forming the original junction on a fiber is in a preferred position to sense the growthpromoting signal indicating that the fiber is becoming receptive to further synaptic input, and it may therefore be induced to sprout earlier than other axons. Since preliminary results (B. M. Nudell and A. D. Grinnell, unpublished observations) indicate that adjacent fibers occasionally are innervated by the same axon, these adjacent branches might also be in a preferred position to respond to a sprouting signal.

\section{References}

Angaut-Petit, D., and A. Mallart (1979) Dual innervation of endplate sites and its consequences for neuromuscular transmission in muscles of adult Xenopus laevis. J. Physiol. (Lond.) 289: 203-218.

Anzenbacher, H., and W. Zenker (1963) Uber die Gössenbeziehung der Muskefasern zu ihren motorischen Endplatten und Nerven. Z. Zellforsch. Mikrosk. Anat. 60: 860-871.

Bennett, M. R., and A. G. Pettigrew (1975) The formation of synapses in amphibian striated muscle during development. J. Physiol. (Lond.) 252: 203-239.

Bennett, M. R., P. A. McGrath, and D. F. Davey (1979) The regression of synapses formed by a foreign nerve in a mature axolotl striated muscle. Brain Res. 173: 451-469.

Betz, W. J., J. H. Caldwell, and R. R. Ribchester (1980a) The effects of partial denervation at birth on the development of muscle fibers and motor units in rat lumbrical muscle. J. Physiol. (Lond.) 303: 265-279.

Betz, W. J., J. H. Caldwell, and R. R. Ribchester (1980b) Sprouting of active nerve terminals in partially inactive muscles of the rat. J Physiol. (Lond.) 303: 281-297.

Brown, M. C., and R. L. Holland (1979) A central role for denervated tissues in causing nerve sprouting. Nature 282: 724-726.

Brown, M. C., and R. Ironton (1978) Sprouting and regression of neuromuscular synapses in partially denervated mammalian muscles. J. Physiol. (Lond.) 278: 325-348.

Brown, M. C., J. K. S. Jansen, and D. Van Essen (1976) Polyneuronal innervation of skeletal muscle in new-born rats and its elimination during maturation. J. Physiol. (Lond.) 261: $387-422$. 
Brown, M. C., R. L. Holland, and R. Ironton (1980) Nodal and terminal sprouting from motor nerves in fast and slow muscles of the mouse. J. Physiol. (Lond.) 306: 493-510.

Brown, M. C., R. L. Holland, and W. G. Hopkins (1981) Motor nerve sprouting. Annu. Rev. Neurosci. 4: 17-42.

Coërs, C. (1955) Les variations structurelles normales et pathologiques de la jonction neuromusculaire. Acta Neurol. Psychiatr. Belg. 55: 741-866.

Cooper, E., J. Diamond, and C. Turner (1977) The effects of nerve section and of colchicine treatment on the density of mechano-sensory nerve endings in salamander skin. J. Physiol. (Lond.) 264: 725-749.

Dennis, M. J., and J. W. Yip (1978) Formation and elimination of foreign synapses on adult salamander muscle. J. Physiol. (Lond). 274: 299-310.

Diamond, J. (1979) The regulation of nerve sprouting by extrinsic influences. In The Neurosciences: Fourth Study Program, F. O. Schmitt and F. G. Worden, eds., pp. 937-955, M. I. T. Press, Cambridge, MA.

Diamond, J., D. Cooper, C. Turner, and L. Macintyre (1976) Trophic regulation of nerve sprouting. Science (NY) 1.93: 371-377.

Drachman, D. D., and F. Witzke (1972) Trophic regulation of acetylcholine sensitivity of muscle: Effect of electrical stimulation. Science 176: 514-516.

Fambrough, D. M. (1979) Control of acetylcholine receptors in skeletal muscle. Physiol. Rev. 59: 165-227.

Fatt, P., and B. Katz (1951) An analysis of the end-plate potential recorded with an intra-cellular electrode. J. Physiol. (Lond.) 115: 320-370.

Frank, E., J. K. S. Jansen, T. Lømo, and R. H. Westgaard (1975) The interaction between foreign and original motor nerves innervating the soleus muscle of rats. J. Physiol. (Lond.) 247: 725-743.

Griffin, G. E., P. E. Williams, and G. Goldspink (1971) Region of longitudinal growth in striated muscle fibres. Nature New Biol. 232: 28-29.

Grimm, L. M. (1971) An evaluation of myotypic respecification in axolotls. J. Exp. Zool. 178: 479-496.

Grinnell, A. D., and A. A. Herrera (1980) Physiological regulation of synaptic effectiveness at frog neuromuscular junctions. J. Physiol. (Lond.) 307: 301-317.

Grinnell, A. D., and A. A. Herrera (1981) Specificity and plasticity of neuromuscular connections: Long-term regulation of motoneuron function. Prog. Neurobiol. 17: 203-282.

Grinnell, A. D., M. B. Rheuben, and M. S. Letinsky (1977) Mutual repression of synaptic efficacy by pairs of foreign nerves innervating frog skeletal muscle. Nature 265: 368-370.

Grinnell, A. D., M. S. Letinsky, and M. B. Rheuben (1979) Competitive interaction between foreign nerves innervating frog skeletal muscle. J. Physiol. (Lond.) 289: 241-262.

Haimann, C., A. Mallart, and N. F. Zilber-Gachelin (1976) Competition between motor nerves in the establishment of neuromuscular junctions in striated muscles of Xenopus laevis. Neurosci. Lett. 3: 15-20.

Haimann, C., A. Mallart, J. Tomàs i Ferré, and N. F. ZilberGachelin (1981a) Patterns of motor innervation in the pectoral muscle of adult Xenopus laevis: Evidence for possible synaptic remodelling. J. Physiol. (Lond.) 310: 241-256.

Haimann, C., A. Mallart, J. Tomàs i. Ferré, and N. F. ZilberGachelin (1981b) Interaction between motor axons from two different nerves reinnervating the pectoral muscle of Xenopus laevis. J. Physiol. (Lond.) 310: 257-272.

Harris, J. B., and R. R. Ribchester (1979) The relationship between endplate size and transmitter release in normal and dystrophic muscles of the mouse. J. Physiol. (Lond.) 296: 245-265.

Herrera, A. A., and A. D. Grinnell (1980) Transmitter release from frog motor terminals depends on motor unit size. Nature
287: 649-651.

Herrera, A. A., and A. D. Grinnell (1981) Contralateral denervation causes enhanced transmitter release from frog motor nerve terminals. Nature 291: 495-497.

Herrera, A. A., and A. D. Grinnell (1982) Glial obstruction, and synaptic strength at frog neuromuscular junctions. Soc. Neurosci. Abstr. 8: 492.

Hoffman, H. (1951) A study of the factors influencing innervation of muscle by implanted nerves. Aust. J. Exp. Biol. Med. Sci. 29: 280-307.

Hutter, O. F., and W. Trautwein (1956) Neuromuscular facilitation by stretch of motor nerve-endings. J. Physiol. (Lond.) 133: $610-625$.

Jansen, J., T. Lømo, K. Nicolaysen, and R. Westgaard (1973) Hyperinnervation of skeletal muscle fibers: Its dependence upon muscle activity. Science 181: 559-561.

Jansen, J. K. S., and D. C. Van Essen (1975) Re-innervation of rat skeletal muscle in the presence of $\alpha$-bungarotoxin. $J$. Physiol. (Lond.) 250: 651-667.

Jansen, J. K. S., W. Thompson, and D. P. Kuffler (1978) The formation and maintenance of synaptic connections as illustrated by studies of the neuromuscular junction. Prog. Brain Res. 48: 3-18.

Karnovsky, M. J. (1964) The localization of cholinesterase activity in rat cardiac muscle by electron microscopy. J. Cell Biol. 23: 217-232.

Katz, B., and S. W. Kuffler (1941) Multiple motor innervation of the frog's sartorius muscle. J. Neurophysiol. 4: 209-223.

Katz, B., and R. Miledi (1977) Transmitter leakage from motor nerve endings. Proc. R. Soc. Lond. (Biol.) 196: 59-72.

Katz, B., and S. Thesleff (1957) On the factors which determine the amplitude of the "miniature end-plate potential." J. Physiol. (Lond.) 137: 267-278.

Kuffler, D., W. Thompson, and J. K. S. Jansen (1977) The elimination of synapses in multiply-innervated skeletal muscle fibres of the rat: Dependence on distance between endplates. Brain Res. 138: 353-358.

Kuffler, D. P., W. Thompson, and J. K. S. Jansen (1980) The fate of foreign endplates in cross-innervated rat soleus muscle. Proc. R. Soc. Lond. (Biol.) 208: 189-222.

Kuffler, S. W. (1952) Incomplete neuromuscular transmission in twitch system of frog's submentalis muscles. Fed. Proc. 11: 87.

Kuno, M., S. A. Turkanis, and J. N. Weakly (1971) Correlation between nerve terminal size and transmitter release at the neuromuscular junction of the frog. J. Physiol. (Lond.) 213: $545-556$.

Letinsky, M. S., and P. DeCino (1980) Histological staining of pre- and postsynaptic components of amphibian neuromuscular junctions. J. Neurocytol. 9: 305-320.

Lømo, T. (1976) The role of activity in the control of membrane and contractile properties of skeletal muscle. In Motor Innervation of Muscle. S. Theslef, ed., pp. 289-321, Academic Press, New York.

Lømo, T., and J. K. S. Jansen (1980) Requirements for the formation and maintenance of neuromuscular connections. Curr. Top. Dev. Biol. 16: 253-281.

Lømo, T., and J. Rosenthal (1972) Control of ACh sensitivity by muscle activity in the rat. J. Physiol. (Lond.) 221: 493513.

Lømo, T., and R. H. Westgaard (1975) Further studies on the control of $\mathrm{ACh}$ by muscle activity in the rat. J. Physiol. (Lond.) 252: 603-626.

Lømo, T., R. H. Westgaard, and H. A. Dahl (1974) Contractile properties of muscle control by pattern of muscle activity in the rat. Proc. R. Soc. Lond. Biol. 187: 99-103.

Luff, A. R., and U. Proske (1976) Properties of motor units of the frog sartorius muscle. J. Physiol. (Lond.) 258: 673-685.

Mark, R. F. (1980) Synaptic repression at neuromuscular junc- 
tions. Physiol. Rev. 60: 355-395.

Martin, A. R. (1955) A further study of the statistical components of the end-plate potential. J. Physiol. (Lond.) 130: 114-122.

McArdle, J. J. (1975) Complex endplate potentials at regenerating neuromuscular junctions of the rat. Exp. Neurol. 49: 629-638.

McLachlan, E. M., and A. R. Martin (1981) Non-linear summation of end-plate potentials in the frog and mouse. J. Physiol. (Lond.) 311: 307-324.

Nudell, B. M., and A. D. Grinnell (1982) Inverse relationship between transmitter release and terminal length in synapses on frog muscle fibers of uniform input resistance. J. Neurosci. 2: 216-224.

O'Brien, R. A. D., A. J. C. Ostberg, and G. Vrbova (1978) Observations on the elimination of polyneuronal inmervation in developing mammalian skeletal muscle. J. Physiol. (Lond.) 282: 571-582.

Purves, D. (1976) The formation and maintenance of synaptic connections. In Function and Formation of Neural Systems, G. S. Stent, ed., pp. 21-49, Dahlem Konferenzen, Berlin.
Purves, D., and J. W. Lichtman (1980) Elimination of synapses in the developing nervous system. Science 210: 153-157.

Ridge, R. M. A. P., and A. M. Thomson (1980) Electrical responses of muscle fibres in a small foot muscle of Xenopus laevis. J. Physiol. (Lond.) 306: 41-49.

Stent, G. (1973) A physiological mechanism for Hebb's postulate of learning. Proc. Natl. Acad. Sci. U. S. A. 70: 997-1001.

Thompson, W., and J. K. S. Jansen (1977) The extent of sprouting of remaining motor units in partly denervated immature and adult rat soleus muscle. Science 2: 523-535.

Turkanis, S. A. (1973) Effects of muscle stretch on transmitter release at endplates of rat diaphragm and frog sartorius muscle. J. Physiol. (Lond.) 230: 391-403.

Weakly, J. N. (1978) Similarities in synaptic efficacy along multiply innervated twitch muscle fibers of the frog: A possible muscle-to-motoneuron interaction. Brain Res. 158: 235239.

Wernig, A., M. Pécot-Dechavassine, and H. Storer (1980) Sprouting and regression of the nerve at the frog neuromuscular junction in normal conditions and after prolonged paralysis with curare. J. Neurocytol. 9: 277-303. 